\title{
SALINITY-DEPENDENT TOXICITIES OF ZINC OXIDE NANOPARTICLES TO THE MARINE DIATOM THALASSIOSIRA PSEUDONANA
}

Mana M.N. Yung ${ }^{1}$, Stella W.Y. Wong ${ }^{1}$, Kevin W.H. Kwok ${ }^{2}$, F.Z. Liu ${ }^{3}$, Y.H. Leung ${ }^{3}$, W.T. Chan ${ }^{4}$, X.Y. Li ${ }^{5}$, A. B. Djurišic ${ }^{3}$ and Kenneth M.Y. Leung ${ }^{1}$

${ }^{1}$ The Swire Institute of Marine Science and School of Biological Sciences, the University of Hong Kong, Hong Kong SAR, China

2 Department of Applied Biology and Chemical Technology, the Hong Kong Polytechnic University, Hong Kong SAR, China

${ }^{3}$ Department of Physics, the University of Hong Kong, Hong Kong SAR, China

${ }^{4}$ Department of Chemistry, the University of Hong Kong, Hong Kong, China;

${ }^{5}$ Department of Civil Engineering, the University of Hong Kong, Hong Kong, China

This study comprehensively investigated the influences of salinity, exposure concentration and time on the aggregate size, surface charge and dissolution of zinc oxide nanoparticles ( $\mathrm{ZnO}-\mathrm{NPs} ; 20 \mathrm{~nm}$ ) in seawater, and examined the interacting effect of salinity and waterborne exposure of $\mathrm{ZnO}$-NPs on the marine diatom Thalassiosira pseudonana for $96 \mathrm{~h}$. We found that aggregate sizes of ZnO-NPs significantly increased with increasing salinity, but generally decreased with increasing exposure concentration. Ion release decreased with increasing salinity, whereas the surface charge of the particles was not affected by salinity. The increased aggregate size and decreased ion release with increasing salinity, and consequently lower concentration of bioavailable zinc ions, resulted in decreased toxicity of ZnO-NPs at higher salinity in general in terms of growth inhibition (IC50) and chlorophyll fluorescence (EC50 - ФPo and EC50 - Ф2). However, IC50s and EC50s of ZnO-NPs were smaller than those of $\mathrm{Zn2}+$ (from $\mathrm{ZnO}-\mathrm{NPs}$ ultrafiltrate and $\mathrm{ZnCl} 2$ ), indicating that dissolved $\mathrm{Zn} 2+$ can only partially explain the toxicity of ZnONPs. SEM images showed that ZnO-NPs attached on the diatom frustule surface, suggesting that the interaction between the nanoparticles and the cell surface may acerbate the toxicity of $\mathrm{ZnO}-\mathrm{NPs}$. Our results linked the physicochemical characteristics of $\mathrm{ZnO}-\mathrm{NPs}$ in seawater with their toxicities to the marine diatom and highlighted the importance of salinity as an influential environmental factor governing the aggregation, dissolution and the toxicity of $\mathrm{ZnO}-\mathrm{NPs}$. 